\title{
Immediate effects of spinal manipulation in pain and global joint mobility in patients with chronic nonspecific low back pain
}

\author{
Walkyria Vilas Boas Fernandes ${ }^{1}$, Franciéli Dall Pizzol ${ }^{2}$, Andrielle Elaine Capote 3 , Sibele de Andrade Melo ${ }^{4}$, \\ Juliana Carvalho Schleder ${ }^{5}$
}

\begin{abstract}
Objective: The aim of this study was to analyze the immediate effects of applying a manipulative intervention on chronic non-specific back pain and increasing global joint mobility. Method: A cross-sectional, randomized, single-blind study was carried out, consisting of 19 women aged between 18 and 55 years old, separated into two groups: Experimental Group (EG = 10) and Control Group (CG=9). The evaluation consisted of a physical examination, Rolland Morris questionnaire, fingertip-to-floor test, Visual Analogue Scale (VAS), and pressure algometry (L5) before and after the manipulative intervention. The EG was submitted to five vertebral manipulations, two in the bilateral pelvis region, one in the middle thoracic region (T5-T7) and two in the bilateral cervical region at the C3 level. The CG was submitted to two placebos manipulative techniques, being positioned in right and left lateral decubitus position for 10 seconds each, in the same position of global pelvic manipulation, but without the manipulative impulse (thrust). Results: The results were statistically significant in the EG in the reduction of sensation of pain $(p<0,001)$ and the increase of overall joint mobility $(p<0,05)$ when comparing pre and post intragroup moments. There were no statistically significant differences in relation to pain threshold evaluated in pressure algometry. Conclusion: It is concluded that a manipulative intervention is able to reduce the pain and to increase the global mobility immediately after its accomplishment.
\end{abstract}

Keywords: Low back pain; Spinal manipulation; Joint mobility.

\section{INTRODUCTION}

Low back pain is characterized as moderate or severe pain, with or without stiffness, and may cause chronic pain that can lead to persistent disability. ${ }^{(1)}$ Its origin ranges from the last ribs to the inferior gluteal folds, which can lead the individual to physical disabilities and decrease in range of motion and flexibility. ${ }^{(2,3)}$

Currently, Physical Therapy has been working through techniques of manual therapy, mobilization and/or spinal manipulation, in solving the factors that trigger the back pain with positive results. ${ }^{(2,3)}$ The spinal manipulation can bring satisfactory results in the reduction of pain syndromes and in the gain of joint mobility, since it causes a neurophysiological effect through the mechanical stimulation of sensory neurons of the capsule of the zigoapophyseal facets, which in a matter of seconds to minutes after the application of the technique, can be observed the decrease of pain..$^{(4,5)}$

When a joint becomes hypomobular due to acute or chronic pathologies, through muscle spasm, muscle weakness or other musculoskeletal changes, its functional movement is temporarily impaired, causing another structure to try to compensate the compensatory hypermobility. ${ }^{(6)}$ Thus, osteopathy considers that patients with low back pain present restricted regions at a distance and may be the cause of low back pain. ${ }^{(7)}$

Several works have already been published involving the treatment of chronic mechanical cervical pain through manipulation of the thoracic spine, showing that a technique of spinal manipulation in a non-specific region may also be effective for the treatment of specific region pain. ${ }^{(8-10)}$ In relation to low back pain, there are very few published works with this line of thought. A recent study ${ }^{(11)}$ with 148 patients with chronic nonspecific low back pain, found that both patients who received manipulation in the thoracic spine and patients who received manipulation in the lumbar spine showed a $30 \%$ improvement in the numerical scale of pain after spinal manipulation. This leads us to believe that treating nonspecific regions (thoracic and cervical) in patients with low back pain can also be effective. 
Thus, the main objective of this study was to verify the immediate effects of a manipulative intervention on chronic non-specific low back pain and increase in global joint mobility, considering that manipulation in the cervical, thoracic and lumbar regions may favor the joint release of specific and nonspecific regions, rebalancing the entire posterior chain.

\section{METHOD}

This was a cross-sectional, randomized, and single blind study approved by the Ethics and Research Committee of the Universidade Estadual do Centro-Oeste, no 49554.

\section{Sample selection}

The study included 19 women with chronic non-specific back pain ${ }^{(12-15)}$ for more than 3 months, aged between 18 and 55 years, and the Roland-Morris questionnaire ${ }^{(16)}$ higher than 3 points. Exclusion criteria were: volunteers undergoing some type of physical therapy or spinal manipulation in the three weeks prior to the study; who were taking anti-inflammatory drugs; with previous surgery in the spine; pregnant women; Patients presenting warning signs of specific low back pain or root syndromes and volunteers who had alterations such as tumor, infectious and inflammatory diseases. ${ }^{(17)}$

\section{Procedures and materials}

The volunteers were randomly divided into two groups, EG (experimental group) and CG (control group).

In the EG The volunteers underwent five vertebral manipulations: a) cervical manipulation at the level of $\mathrm{C}^{(18)}$ bilaterally; b) Supine thoracic manipulation - Dog Technique $(\mathrm{T} 5-\mathrm{T} 8)^{(19)}$; c) Manipulation of the pelvis that involves the sacrum, iliac and $\mathrm{L} 4-\mathrm{L} 5^{(6)}$ bilaterally.

In the CG, the volunteers underwent a placebo manipulation maneuver, where the volunteers were positioned in the right and left lateral decubitus for 10 seconds $^{(3,20,21)}$ being in the same position of global pelvic manipulation, but without the accomplishment of the manipulative impulse (thrust).

Before the manipulative intervention (EG) or placebo technique (CG), the volunteers underwent a clinical evaluation (anamnesis and clinical examination) and answered the Roland-Morris Questionnaire. ${ }^{(16)}$ They then performed the fingertips-to-floor test to assess the increase in overall joint mobility. For this, a $15 \mathrm{~cm}$ platform was used and the variable was obtained by the distance from the tip of the middle finger of the dominant side to the floor. ${ }^{(22)}$ The volunteers performed 3 trunk-flexion movements for training and standardization, and 3 other times to obtain pre-intervention data. To measure the pain, was applied the Visual Analogue Scale (VAS), being zero (0) defined as "complete absence of pain" and 10 (ten) as "the worst pain ever felt". Studies describe this tool as useful for classifying pain, being reproducible, reliable and sensitive to clinical changes. ${ }^{(23,24)}$ Pressure algometry, was performed three times in the $L 5$ before the manipulative intervention by a trained physiotherapist. ${ }^{(10,11)}$ For the presentation of the results, the third measurement was used. The fingertips-tofloor test, VAS and algometry were performed again after the intervention. The evaluations were carried out by the researcher 1 while the intervention by the researcher 2 .

\section{Statistical Analysis}

After proving the normality of the sample by the Shapiro-Wilk test $(p \geq 0.05)$ and the homogeneity of variances by Levene test $(p>0.05)$, was performed and two factors ANOVA to comparison of the pre, post and intergroup conditions. This analysis revealed only intragroup differences between pre and post conditions, so it was decided to proceed with the paired $t$ test to compare the effect of treatment in each group separately.

For this analysis was used the SPSS software version 18.0 , and considered the values of $p<0.05$ with statistical significance.

\section{RESULTS}

The anthropometric characteristics of the subjects in each group are presented in table 1 , confirming the homogeneity of the groups in relation to the presented variables.

In the pre- and post-intragroup comparisons, statistically significant differences were observed between VAS values (Figure 1) and the fingertips-to-floor test (Figure 2), exclusively in the EG.

Regarding the VAS values, a decrease was observed in the EG (3.77 \pm 1.66 in the pre and $2.45 \pm 1.57$ in the post) in relation to the CG $(3.56 \pm 1.58$ in the pre and $3.70 \pm 1.9$ in the post).

Regarding the values of the fingertips-to-floor test it was also observed a decreased in the EG $(20.5 \pm 12.5$ in the pre and $18.5 \pm 12.8$ in the post) in relation to the CG $(19.0 \pm 9.68$ in the pre and $19.1 \pm 10$ in the post).

Table 1 - Characterization of the sample.

\begin{tabular}{|c|c|c|c|c|c|c|}
\hline & Age (years) & Time of pain (years) & Rolland-Morris & Weight (Kg) & Height (m) & $\begin{array}{c}\text { BMI } \\
\mathrm{Kg} / \mathrm{m}^{2}\end{array}$ \\
\hline Experimental Group & $25.1 \pm 9.40$ & $1.85 \pm 2.42$ & $5.80 \pm 3.99$ & $62.3 \pm 8.88$ & $1.66 \pm 0.06$ & $22.5 \pm 3.47$ \\
\hline Control Group & $31.2 \pm 13.18$ & $3.10 \pm 2.01$ & $5.70 \pm 4.08$ & $65.7 \pm 13.6$ & $1.63 \pm 0.09$ & $24.7 \pm 5.13$ \\
\hline Levene test $(p)$ & 0.249 & 0.222 & 0.956 & 0.517 & 0.304 & 0.265 \\
\hline
\end{tabular}

The values of $p>0.05$ indicated that no significant differences were found in the variables between groups. 
For the values of pressure algometry immediately after vertebral manipulation, no significant differences were found in either group (Figure 3), being considered similar the EG values $(5.55 \pm 2.24$ in the pre and $6.55 \pm 2.60$ in the post) and the CG values $(6.53 \pm 1.77$ in the pre and $6.62 \pm 2.98$ in the post).

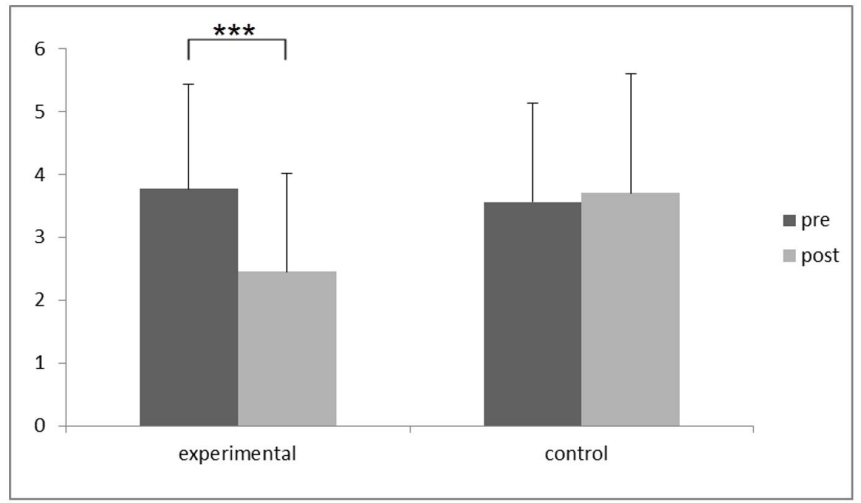

Figure 1 - VAS values in the pre and post evaluations. Note $(* * *)$ : The values of $p<0.001$ indicated that statistical significant differences were found in the variables.

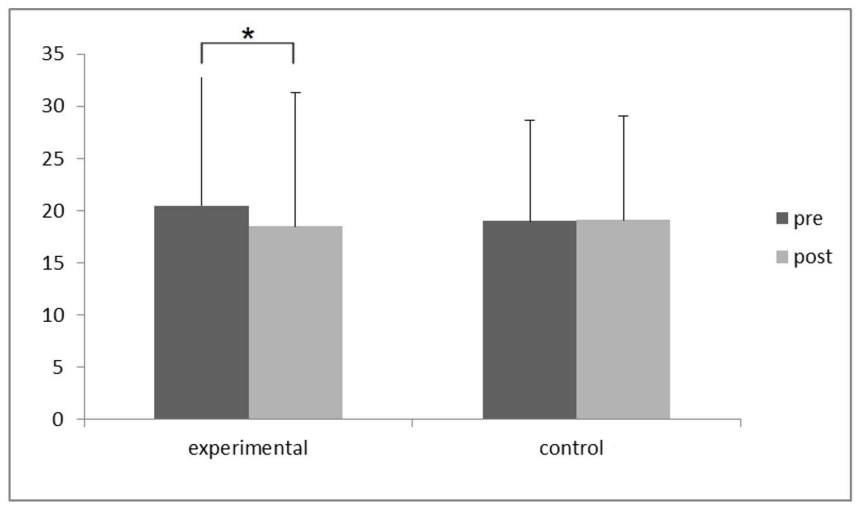

Figure 2 - Values of the fingertips-to-floor test $(\mathrm{cm})$ in the pre and post evaluations. Note $(*)$ : The values of $p<0.05$ indicated that statistical significant differences were found in the variables.

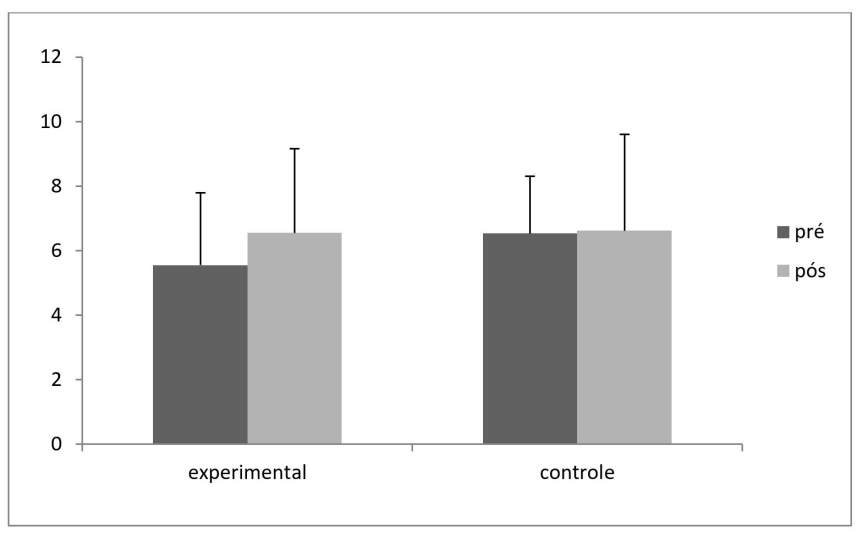

Figure 3 - Values of the pressure algometry $(\mathrm{kg} / \mathrm{mmHg})$ in the pre and post $\mathrm{L} 5$ evaluations. The values of $p>0.05$ indicated that no significant differences were found between the groups.

\section{DISCUSSION}

The initial hypothesis that the combination of spinal manipulation in specific and nonspecific regions could decrease low back pain and increase overall joint mobility was proven in this study. The results show a statistically significant decrease between the moments before and after manipulative intervention in the EG. These results are in line with other studies that have shown that the main goals of manipulation are to increase joint mobility ${ }^{(6,25)}$, attenuate the activity of motor neurons ${ }^{(26)}$, remove muscle spasms $s^{(27,28,29)}$ and decrease the sensation of pain. ${ }^{(4,27,29,30)}$

It is worth noting the validity of using VAS for the evaluation of pain intensity, our study showed a statistically significant reduction (Figure 1 ) of the VAS measurements immediately after the manipulations in the EG group, which demonstrates that the manipulative techniques showed immediately effective in reducing pain, confirming other authors ${ }^{(33-35)}$ that the spinal manipulation leads to a decrease in the sensation of pain, provoking analgesic effects.

Similar results have also been demonstrated in other studies with immediate pain reduction ${ }^{(3,31,33)}$ and in long term. ${ }^{(34,35)}$ What differentiates our work from other previous studies is that the techniques are usually performed only in the specific regions of pain, and in our study three interventions were performed, one in the specific region (lumbar) and two in non-specific regions (cervical and thoracic), showing that the combination of techniques may be more effective in the treatment of low back pain. One study analyzed the effects of the manipulative technique in a specific region in $\mathrm{G} 1$ group and in another non-specific region in $\mathrm{G} 2$ group, showing that in both groups the intervention was effective in reducing pain in $30 \%$, but without finding statistically significant differences between groups. ${ }^{(11)}$

In the CG there was a small increase in VAS values, it is believed that the anterior flexion movement may have aggravated the sensation of pain in most of the volunteers and that also the positioning in right and left lateral decubitus maintained for 10 seconds each without the realization of thrust may have caused some muscular spasm, the same did not occur in the EG, since the manipulative maneuvers were performed completely.

The same occurred in two studies ${ }^{(3,31)}$, in which the mean of VAS decreased in the experimental group after the manipulation and increased in the control group, and the volunteers in the control group were only in the manipulation position for 10 seconds, but without finalizing it. Similar results, however, without pain reduction in the EG, were reported by a study ${ }^{(36)}$, in which the experimental group received a lumbar manipulation in L3 level and the control group was placed in lateral decubitus position for 5 seconds. No statistically significant change was found in the EG in relation to VAS, but in CG was found a statistically significant increase.

Regarding the joint mobility before and after spinal manipulations in which it was used the fingertips-to-floor test, 
considered a highly reliable and reproducible test ${ }^{(22)}$, the values immediately after the manipulations were significantly lower in the EG (Figure 2). This result suggests that spinal manipulation positively influences the increase of global joint mobility, reinforcing the idea of Keller et al ${ }^{(37)}$ and Bicalho et al. ${ }^{(3)}$

In this study, it was also used as an evaluation method the pressure algometry ${ }^{(10,11)}$, In order to evaluate the pain threshold before and after vertebral manipulations in the L5. In EG the results after manipulation obtained a small increase in the pain threshold (Figure 3), but their results were not statistically significant for the study. In CG, pre and post results were practically the same.

Finally, contrary to the initial hypothesis, it was not possible to find statistically significant results for the increase of the pain threshold. The same occurred in a study ${ }^{(11)}$ in which the algometry was performed in the L3 spinous process and $5 \mathrm{~cm}$ laterally to the $L 5$ spinous process. The results were also not satisfactory for the increase of the pain threshold, not showing statistically significant differences in patients with low back pain. These results were against the researches that supports the hypothesis that spinal manipulation would rather increase pain threshold. ${ }^{(27,30,32)}$

\section{CONCLUSION}

The manipulative intervention applied in the specific and non-specific region of the pain is able to reduce the intensity of low back pain and to provide an increase in the global joint mobility immediately after its accomplishment, proving to be effective in the short-term treatment in patients with chronic nonspecific low back pain. Regarding pressure algometry, no statistically significant differences were found in this study.

It is suggested that further studies be performed using the combination of techniques in specific and non-specific regions in the short and long term, so that we can verify the best combinations of techniques in the treatment of patients with chronic nonspecific low back pain.

\section{AUTHOR'S CONTRIBUTION}

WVBF e FDP: writing, data collection; SAM: statistical analysis and review; AEC: review and corrections; JCS: review.

\section{CONFLICTS OF INTEREST}

The authors declare that there is no conflict of interest.

\section{AUTHOR DETAILS}

2 Physiotherapist, Universidade Estadual do Centro-Oeste, Chopinzinho (PR), Brazil. 3 Master in Physiology, Universidade Federal do Paraná, Curitiba (PR), Brazil. 4 Professor of the Physiotherapy course, Universidade Estadual do Centro-Oeste, Chopinzinho (PR), Brazil. 5 Doctor in Physiology, Universidade Federal do Paraná, Curitiba (PR), Brazil.

\section{REFERENCES}

1. Waddell G. The back pain revolution. 1 ed. Edinburgh: Churchill Livingstone. 1998. Macedo, DDP. Lombalgias. Cien Cult. 2011;63(2):13.
2. Triano J, Mcgregor M, Hondras MA, Brennan PC. Manipulative therapy versus education programs in chronic low back pain. Spine. 1995;20:948955.

3. Bicalho E, Setti JAP, Macagnan J, Cano JLR, Manffra EF. Immediate effects of a high-velocity spine manipulation in paraspinal muscles activity of nonspecific chronic low-back pain subjects. Man Ther. 2010;15(5):469-75.

4. Wright, A. Hyphoalgesia post manipulative therapy: a review of a potential neurophysiological mechanism. Man Ther. 1995;1:11-6.

5. Lanuzzi A, Khaisa P. Comparison of human lumbar facet joint capsule strains during simulated high-velocity, low-amplitude spinal manipulation versus phisiological motions. Spine. 2005; 5(3):9-12.

6. Ricard, F. Tratamiento osteopático de las lumbalgias y lumbociáticas por hernias discales Ciáticas. 1a ed. Editora Médica Panamericana: Madrid, España. 2003.

7. Franke H, Franke J, Fryer G. Osteopathic manipulative treatment for nonspecific low back pain: a systematic review and meta-analysis. BMC Musculoskeletal Disorders. 2014;15:286.

8. Salvatori R, Rowe RH, Osborne R, Beneciuk JM. Use of thoracic spine thrust manipulation for neck pain and headache in a patient following multiple-level anterior cervical discectomy and fusion: a case report. J Orthop Sports Phys Ther. 2014;44(6):440-9. doi: 10.2519/jospt.2014.5026.

9. Salom-Moreno J, Ortega-Santiago R, Cleland JA, Palacios-Ceña M, TruyolsDomínguez S, Fernández-de-las-Peñas C. Immediate changes in neck pain intensity and widespread pressure pain sensitivity in patients with bilateral chronic mechanical neck pain: a randomized controlled trial of thoracic thrust manipulation vs non-thrust mobilization. J Manipulative Physiol Ther. 2014;37(5):312-9. doi: 10.1016/j.jmpt.2014.03.003.

10. Casanova-Méndez A, Oliva-Pascual-Vaca A, Rodriguez-Blanco C, HerediaRizo AM, Gogorza-Arroitaonandia K, Almazán-Campos G. Comparative short-term effects of two thoracic spinal manipulation techniques in subjects with chronic mechanical neck pain: a randomized controlled trial. Man Ther. 2014;19(4):331-7. doi: 10.1016/j.math.2014.03.002.

11. Oliveira RF, Liebano RE, Costa LCM, Rissato LL, Costa LOP. Immediate Effects of Region-Specific and Non- Region-Specific Spinal Manipulative Therapy in Patients With Chronic Low Back Pain: A Randomized Controlled Trial. Phys Ther. 2013;93:748-56.

12. Walker BF, Williamson OD. Mechanical or inflammatory low back pain. What are the potential signs and symptoms? Manual Therapy. 2009;14:314-20.

13. Abbott $H$, Fritz JM, Mccane B, Shultz B, Herbison P, Lyons B, et al. Lumbar segmental mobility disorders: comparison of two methods of defining abnormal displacement kinematics in a cohort of patients with nonspecific mechanical low back pain. BMC Musculoskeletal Disorders. 2006;7:45.

14. Al-Eisa E, Egan D, Deluzio K, Wassersug R. Effects of pelvic skeletal asymmetry on trunks movement. Three dimensional analysis in healthy individuals versus patients with mechanical low back pain. Spine. 2006;3(3):71-9.

15. Valat JP. Factors involved in progression to chronicity of mechanical low back pain. Joint Bone Spine. 2005;72,3:193-5.

16. Nusbaum L, Natour J, Ferraz MB, Goldenberg J. Translation, adaptation and validation of the Roland-Morris questionnaire - Brazil Roland-Morris. Braz J Med Biol Res. 2001;34(2):203-10.

17. Koes B, Tulder M, Thomas S. Diagnosis and treatment of low back pain. BMJ. 2006;332:1430-34.

18. Ricard F. Tratamiento Osteopático de las Algias de Origen Cervical. 1aㅡ ed. Editora Médica Panamericana: Madrid, España. 2008.

19. Ricard F. Tratamento Osteopático da Caixa Torácica. 1a ed. Editora Saber Saúde: Campinas. 2008.

20. Ritvanen T, Zaproudina N, Nissen M, Leinoven V, Hannine O. Dynamic surface electromyographic responses in chronic low back pain treated by traditional bone setting and conventional physical therapy. Journal of Manipulative and Physiological Therapeutics 2007;30(1):31-7. doi:10.1016/j.jmpt.2006.11.010. 
21. Lalanne K, Lafond D, Descarreaux M. Modulation of the flexion_relaxation response by spinal manipulative therapy: a control group study. Journal of Manipulative and Physiological Therapeutics 2009;32(3):203-9.

22. Gauvin MG, Riddle DI, Rothstein Jm. Reliability of clinical measurements of forward bending using the modified fingertips-to-floor method. Physical Therapy. 1990;70:443-7.

23. Wewers Me, Lowe NK. A critical review of visual analogue scales in measurement of clinical phenomena. Res Nurs Health. 1990;13:227-236.

24. Maxwell C. Sensitivity and accuracy of the visual analogue scale: a psychophysical classroom experiment. J. Clin. Pharmacol. 1978;6:15-24.

25. Keller T, Colloca C, Gunzburg R. Neuromechanical characterization of in vivo lumbar spinal manipulation. Part I. Vertebral motion. J Manipulative Physiol Ther. 2003;26(9):567-78.

26. Dishmann D, Bulbulian R. Spinal Reflex Attenuation Associated with Spinal Manilation. Spine. 2000;25(19):2519-25.

27. Pickar J. Neurophysiological effects of spinal manipulation. Spine. 2002;22:357-71.

28. Devocht J, Pickar J, Wilder D. Spinal Manipulation Alters Electromyographc Activity of Paraspinal Muscle: A Descriptive Study. J Manipulative Physiol Ther. 2005;28(7):465-71.

29. Ernest E. A systematic review of systematic reviews of spinal manipulation. The Royal Society of Medicine. 2006;99:122-6.

30. George S, Bishop M, Bialosky J, Zeppieri G, Robinson M. Immediate effects os spinal manipulation on thermal pain sensitivity: an experimental study. BMC Musculoskeletal Disorder. 2006;68(7):147-84.
31. Fernandes VBW. Efeitos da Manipulação Vertebral de Alta Velocidade na Resposta Eletromiográfica e Cinemática durante o movimento de flexão/ extensão em indivíduos com dor lombar crônica mecânica [Dissertação de mestrado]. Curitiba: PUC-PR. 2011.

32. Maigne J, Vautraver P. Mode d"action dês manipulations vertébrales. Revue du Rhumatisme. 2003;70:713-19.

33. Cecchi F, Molino-Lova R, Chiti M, Pasquini G, Paperini A, Conti AA, et al. Spinal manipulation compared with back school and with individually delivered physiotherapy for the treatment of chronic low back pain: a randomized trial with one-year follow-up. Clin Rehabil. 2010;24(1):26-36.

34. Aure OF, Nilsen JH, Vasseljen O. Manual therapy and exercise therapy in patients with chronic low back pain: a randomized, controlled trial with 1-year follow-up. Spine. 2003;28(6):525-32.

35. Hondras MA, Long CR, Cao Y, Rowell RM, Meeker WC. A randomized controlled trial comparing 2 types of spinal manipulation and minimal conservative medical care for adults 55 years and older with subacute or chronic low back pain. J Manipulative Physiol Ther. 2009;32(5):330-43.

36. Harvey MP, Descarreaux M. Short term modulation of trunk neuromuscular responses following spinal manipulation: a control group study. Musculoskelet Discord.2013;14(92). doi:10.1186/1471-2474-14-92.

37. Keller TS, Colloca JC, Moore JC, Gunzburg R, Harrinson D. Increased multiaxial lumbar motion responses during multiple-impulse mechanical force manually assisted spinal manipulation. Chiropr Osteopat. 2006;14(1):2-8. 